\title{
Enraizamento social do mercado no Brasil: uma abordagem a partir da economia política institucionalista e dos intérpretes do Brasil
}

\section{Hélio Afonso de Aguilar Filho ${ }^{1}$}

"Brazilians couldn't organize a piss up in a brewery" (Anonymous British Tourist visiting Brazil).

Resumo: O presente trabalho aborda uma categoria central na análise econômica, o mercado. Assume, com base no referencial teórico da economia política institucionalista, dois pressupostos: $1^{\circ}$ ) que os mercados são instituições enraizadas histórica e socialmente e $2^{\circ}$ ) que a noção de mercado livre, tão importante para o liberalismo ortodoxo, é insustentável, dado que a abrangência do mercado é também uma construção social que muda conforme a época e a interação das forças políticas. Uma análise mais específica do enraizamento dessa instituição e das suas determinaç̧ões políticas será feita observando-se as formulações dos chamados Intérpretes do Brasil. Com essa literatura buscar-se-á mostrar que no Brasil, os mercados se desenvolveram apropriados por grupos de interesses, acarretando distorções em seus mecanismos de incentivos. Várias razões são apresentadas para essa apropriação, incluindo desde a influência do patrimonialismo herdado de Portugal até a dependência econômica do país. O presente trabalho, contudo, segue a interpretação mais recente que identifica a estrutura extremamente desigual e excludente da distribuição de riqueza como a causa das distorções no funcionamento do mercado.

Palavras-chave: Mercado. Economia. Institucionalismo. Enraizamento. Intérpretes do Brasil. Classificação JEL B31, B52, N16

\begin{abstract}
This paper studies the market, a central category in economic analysis, from the theoretical framework of institutionalist political economy. Two premises are assumed: 1) Firstly, markets are institutions rooted in history and society, and 2) Secondly the concept of a free market, which is important for orthodox arguments, is unsustainable because the market is a social construction that changes in time and is influenced by political forces. A specific analysis of the embeddedness of this institution and its political determinations will be performed, observing the formulations of the so-called "Interpreters of Brazil". From these interpretations, this paper will try to show that Brazilian markets have worked appropriated by powerful groups of interest, distorting its incentive mechanisms. Several explanations for this appropriation have been presented, including the influence of Portuguese patrimonialism and the type of economic dependence established during colonization. The present paper, however, follows the most recent interpretation which identifies the extremely unequal and exclusionary structure of wealth distribution as the cause of the lack of functionality of the market.
\end{abstract}

Keywords: Market. Economy. Institutionalism. Embeddedness. Brazilian's Interpreters. JEL classification codes: B31, B52, N16.

\footnotetext{
${ }^{1}$ Doutor em Economia pela Universidade Federal do Rio Grande do Sul (UFRGS) e Professor Adjunto da Universidade Federal do Rio Grande do Sul. E-mail: haaf@ufrgs.br
}

Página 86 Caderno de Ciências Sociais Aplicadas, Vitória da Conquista/BA, vol. 16, n 27, ano 16, p. 86-108, jan/jun 2019. 


\section{Introdução}

Muito se discute sobre a relação entre ideologia e teoria econômica. De um lado há os que afirmam ser a teoria econômica dominante uma mera tentativa de justificar o funcionamento do sistema capitalista; de outro, os que afirmam a independência desta em relação a interesses sociais específicos, ou seja, sua neutralidade e objetividade científica.

Apesar da diversidade de perspectivas, o que une de fato várias escolas de pensamento à corrente dominante parece ser a adesão a certos procedimentos matemáticos, baseados na noção de sistemas fechados (LAWSON, 2015) ${ }^{2}$. Mas, pode-se notar também entre algumas destas escolas, certo consenso em termos de recomendações práticas de política econômica; se é algo acidental ou não, essa é uma questão em aberto. O que é compartilhado gira em torno da centralidade do mercado na organização econômica das sociedades modernas. Assim, autores afiliados às escolas Neoclássicas, Novo Clássica, Escolha Pública e a Nova Economia Institucional (NEI) se juntam à tradição econômica liberal para sustentarem a noção de economia de trocas, segunda a qual os indivíduos agindo em prol do auto interesse, ao terem garantidos a ordem e os direitos de propriedade, vão contribuir de forma mais ampla para o bem estar coletivo.

Uma conjectura possível de ser feita é que mesmo dentro da corrente principal e sua noção de autointeresse, é difícil sustentar a lógica do funcionamento do mercado livre. Isto porque a existência do mercado, assim como de toda ordem social, depende da disposição em cumprir regras. Quando agentes buscando o autointeresse operam em ambientes em que é possível disfarçar a ação oportunista, fica difícil garantir a ordem social. Esse raciocínio, contudo, raramente é estendido à compreensão do funcionamento do próprio mercado, onde preferências e regras institucionais são pressupostas. A exceção é a NEI, cujo marco teórico afirma a importância das instituições sociais. A falha desta reside em tratar a emergência e funcionamento das instituições apenas em termos da sua eficiência comparativa.

Em oposição à corrente dominante, a economia política institucionalista de Geoffrey Hodgson, Ha-Joon Chang e Peter Evans salienta, em primeiro lugar, que o mercado é uma instituição cuja criação e funcionamentos estão imersos no social e dependem de decisões políticas. Em segundo, essa

\footnotetext{
${ }^{2} \mathrm{O}$ que une a corrente dominante em economia é uma ontologia baseada em sistemas fechados: a busca é por estabelecer regularidades no nível dos eventos. Já a heterodoxia trabalha com uma ontologia aberta, ao pressupor a existência de fenômenos emergentes. O que diferencia as correntes heterodoxas entre si não são critérios ontológicos ou questões substantivas, mas a preocupação com problemas particulares de áreas específicas ou questões de interesse (institucionalismo radical, marxismo, pós-keynesianos, economia feminista e a escola austríaca são algumas delas).
}

Página 87 Caderno de Ciências Sociais Aplicadas, Vitória da Conquista/BA, vol. 16, n 27, ano 16, p. 86-108, jan/jun 2019. 
abordagem destaca que a noção de mercado livre, tão cara às vertentes liberais do mainstream, é uma ficção, pois o conteúdo compreendido pelo mercado e, desse modo, a sua abrangência, muda conforme a época e a sociedade, fazendo deste uma construção social. Em terceiro lugar, os referidos autores apontam que a relação entre Estado e mercado não é de oposição, mas de complemento. Neste caso, a lógica da captura de renda preconizada pelos teóricos da Escolha Pública, tenderá a ocorrer em Estados desenraizados socialmente. Nele, funcionários transformam serviços públicos, direitos dos cidadãos, em bens privados comercializáveis.

O presente trabalho aborda a questão do enraizamento e da abrangência do mercado por meio das formulações dos chamados Intérpretes do Brasil. Com isso, busca-se mostrar que os mercados no Brasil se desenvolveram apropriados geralmente por grupos de interesses particularistas, acarretando distorções em seus mecanismos de incentivos. Conforme se pretende mostrar também, a estrutura extremamente desigual e excludente da distribuição de renda se constitui na explicação mais plausível para entender essa apropriação. A justificativa para esse estudo é que, apesar de o mercado ser a categoria principal na análise econômica dominante, esta abordagem falha quando deixa de reconhecer que não existem mercados em geral, mas mercados criados a partir de arranjos institucionais específicos. Outrossim, falha também quando se limita a compreender os mercados como arranjos contratuais estabelecidos por agentes econômicos auto interessados.

Este artigo se divide da seguinte forma. Além desta introdução, consta uma segunda seção onde se apresenta a visão dominante sobre o funcionamento do mercado e sua relação com o Estado. $\mathrm{Na}$ terceira seção apresenta-se uma discussão sobre o enraizamento do mercado a partir da visão institucionalista. Na quarta seção, discute-se o caso do Brasil, na ótica dos Intérpretes, destacando os tipos de enraizamento do mercado existentes. E por fim, segue a conclusão do trabalho.

\section{A tradição econômica dominante e o funcionamento do mercado}

Adam Smith é considerado por grande parte da literatura econômica como o fundador da moderna Ciência Econômica. Seus escritos se constituem em um dos primeiros a preconizar a respeito das vantagens da divisão do trabalho e da livre troca em um mundo concorrencial para a produção da riqueza social. O autor escocês acaba consagrando a expressão "mão invisível”, ao descrever situações nas quais a interação entre agentes egoístas e autointeressados resultaria no mais alto nível de bem-estar para a sociedade, mesmo sem uma entidade coordenadora do interesse comum. A busca do interesse próprio e não o altruísmo e a benevolência é que coordenam a ação coletiva. As ideias de Smith 
tornaram-se algo consensual entre diversos pensadores sociais, constituindo-se no ponto de partida para a ortodoxia liberal afirmar as vantagens do mercado autorregulado.

A diferença para diversos dos seus seguidores é que, apesar de advogar a superioridade do mercado em relação a outras formas de alocação de riqueza e transferência de propriedade, Smith nunca procurou estender o comportamento típico dessa esfera a toda economia, nem tampouco às outras instâncias da vida social. Essa tarefa coube à tradição neoclássica com a sustentação do atomismo metodológico e do racionalismo. O primeiro implica ver a sociedade como aglomerado de átomos individuais; o segundo busca explicar a ação humana com base na relação entre "meios" e "fins", pressupondo "meios" escassos e usos múltiplos para os "fins". A partir disso, os neoclássicos chegam a conceber um sistema geral para permitir avaliar as consequências sobre os outros mercados e compreender as interações e os mecanismos que atuam no sentido de levar a economia como um todo a uma situação de equilíbrio. No estudo das questões do bem-estar, desenvolveram teoremas para determinar simultaneamente a eficiência alocativa e a distribuição de renda gerada por esta ${ }^{3}$.

Deve-se incluir dentro do consenso dominante, a Escola de Chicago, com os trabalhos de Milton Friedman, George Stigler e Gary Becker ${ }^{4}$, dentre outros. Para Friedman (1985), expoente mais conhecido desta vertente, o mercado livre não elimina a necessidade do governo, mas diminui sensivelmente o número de questões que a política deve resolver. As vantagens do intercâmbio envolvendo trocas voluntárias, é que este exige menos conformidade em relação ao intercâmbio político. As trocas no mercado, garantida a ordem social e a propriedade privada, permitem às pessoas participarem de um amplo sistema de cooperação voluntária, usufruindo dos benefícios da especialização e da divisão do trabalho. Os resultados, portanto, estão de acordo sempre com as preferências dos indivíduos, já que não há coerção e só há engajamento em trocas que forem convenientes para cada um. Já o intercâmbio político depende de conformidade ou sujeição à vontade alheia. No caso dos sistemas ditatoriais, à vontade de um ditador; no caso da democracia, à vontade da maioria. Há, segundo o autor, na democracia, situações inclusive onde o pleito pode levar a uma condição de tensão fundamental, esgarçando o tecido da sociedade.

\footnotetext{
${ }^{3}$ Existem dois teoremas associados à medida do bem estar social. O primeiro, segundo a qual alcançada determinada condição de equilíbrio nas trocas, não seria possível melhorar a condição de qualquer agente sem prejudicar outro único agente, este seria o ótimo de Pareto. O segundo teorema, procura diferenciar as funções alocativas e distributivas do mercado, ao afirmar que o sistema de preços é o melhor sinalizador da escassez dos recursos. Em consequência, o espaço para a intervenção do Estado na economia seria apenas na distribuição das dotações aos agentes.

4 Esses dois últimos aprofundam os trabalhos da economia neoclássica, no que foi conhecido como abordagem das Escolhas Racionais. Para estes, a combinação das noções de comportamento otimizador, equilíbrio de mercado e preferências estáveis, constitui-se em ponto de partida do enfoque econômico.
}

Página 89 Caderno de Ciências Sociais Aplicadas, Vitória da Conquista/BA, vol. 16, n 27, ano 16, p. 86-108, jan/jun 2019. 
O reconhecimento ainda que modesto de Friedman (1985) sobre as necessidades de intervenção do Estado na economia faz parte da tendência inaugurada depois da Segunda Guerra Mundial. Algumas linhas de pesquisas dentro do neoclassicismo, ao basearem seus trabalhos na noção de interesse individual, passaram a destacar resultados de pesquisa opostos aos da otimização social. $\mathrm{O}$ primeiro resultado, ligado à economia matemática, dá-se com o dilema dos prisioneiros presente na teoria dos jogos. Um segundo ocorre a partir da incorporação de elementos supostamente keynesianos ao mainstream econômico, de onde nasce o reconhecimento das denominadas falhas de mercado, a saber, poder de mercado, problemas de informação, externalidades e bens públicos ${ }^{5}$.

\subsection{Ação Coletiva e Instituições na Tradição Dominante}

Dentro do mainstream, a "ordem pública" aparece como pressuposta na análise econômica. O mercado nasce de forma espontânea, fomentando a cooperação desde que os princípios da lei e da propriedade estejam garantidos de antemão.

O pressuposto de que os grupos sociais, movidos por agentes racionais, tendem natural e espontaneamente a agir para a realização de interesses comuns, é severamente questionado por Mancur Olson em seu livro, “A Lógica da Ação Coletiva”, publicado em 1965 (1999). O autor chama a atenção para o caráter problemático da provisão dos chamados "bens públicos" quando entendido a partir dos princípios de maximização da utilidade marginal. Na sua visão, "mesmo que todos os indivíduos de um grupo sejam racionais e centrados em seus próprios interesses, e que saiam ganhando se, como grupo, agirem para atingir seus objetivos comuns, ainda assim eles não agirão voluntariamente para promover esses interesses comuns e grupais" (OLSON, 1999, p.14). Isto ocorre inclusive nos casos em que o custo da cooperação é baixo, porque, mesmo sendo nula a sua contribuição para a consecução do benefício coletivo, o indivíduo poderia, em certas circunstâncias, usufruir de igual modo do bem em questão.

\footnotetext{
${ }^{5}$ Parte dos bens com que as pessoas defrontam-se envolve duas características importantes, eles são rivais e excludentes. Um bem é rival se o uso que alguém faz dele impede outras pessoas de usar a mesma unidade de bem. Um bem é excludente quando é possível impedir que alguém o use. No caso dos bens públicos eles não são nem rivais nem excludentes, enquanto os bens comuns são rivais, mas não excludentes. Em ambos os casos, a solução para o provimento dos bens será não ótima do ponto de vista econômico. Para os bens públicos, devido à impossibilidade de discriminação entre os que vão usufruir do bem, há um incentivo para os agentes pegarem "carona" quando este bem é fornecido privadamente.
}

Página 90 Caderno de Ciências Sociais Aplicadas, Vitória da Conquista/BA, vol. 16, n 27, ano 16, p. 86-108, jan/jun 2019. 
A conclusão de Olson (1999) é que para os grupos extensos (latentes) ${ }^{6}$ a cooperação é difícil de ser conseguida, porque a racionalidade individual vai guiar os indivíduos para a deserção, apesar da recompensa mais vantajosa em termos agregados ser a cooperação de cada agente independente. A solução passa a ser oferecer incentivos seletivos ou a coerção para haver oferta desses bens.

O problema, seguindo a lógica de Mancur Olson, é que quando se leva a metáfora do homo economicus ao extremo, a própria existência do mercado fica comprometida, em decorrência da impossibilidade de discriminar aqueles que contribuem para o seu funcionamento daqueles que não o fazem. Isto é, como os custos individuais para sustentar os mercados são maiores que zero e a contribuição de cada um não é percebida pelos demais participantes, os ganhos tomados individualmente serão maiores se cada um adotar um comportamento oportunista, deixando de cumprir sua parte nos contratos. E, sem garantias de cumprimento dos contratos, não é possível a existência dos mercados.

O dilema que a abordagem da ação coletiva coloca é que para as sociedades complexas de hoje, a possibilidade de fomentar a cooperação e sustentar a existência de mercados competitivos é ainda mais difícil. Nelas, o número de agentes econômicos e de interações são maiores, sendo mais fácil disfarçar o comportamento oportunista. No entanto, como demonstra a experiência de vários países desenvolvidos, estes mercados existem e seus resultados são perceptíveis. A principal preocupação da NEI é em desenvolver uma teoria que supere os problemas colocados pela abordagem de Olson (1999), ou seja, explique as possibilidades de assentar uma ordem social baseada em agentes autointeressados. Para os afiliados dessa corrente, estudar o desempenho econômico significa entender as instituições que estruturam as relações sociais, políticas e econômicas. As instituições são vistas como as regras do jogo, ao mesmo tempo em que restringem o comportamento individual, incentivam a cooperação e proveem as soluções para superar custos.

Os novos institucionalistas iniciam sua abordagem levantando uma série de objeções em relação à concepção de mercado preconizada pela teoria neoclássica. Seus praticantes chamam atenção para a necessidade de compreender como as fricções, que tem origem nas incertezas e na capacidade racional limitada dos seres humanos, produzem resultados econômicos tão amplamente divergentes entre as sociedades. Para North (1977, p.709), “o padrão de mercado não se tornou absolutamente dominante nem mesmo no século XIX. Na sua ausência, algumas estruturas informais foram e são até hoje

\footnotetext{
${ }^{6}$ Grupos cujos membros se deparam com a percepção de que a contribuição individual para a provisão de bens coletivos não é notada pelos demais em relação ao benefício coletivo são classificados como "latentes".
}

Página 91 Caderno de Ciências Sociais Aplicadas, Vitória da Conquista/BA, vol. 16, nº 27, ano 16, p. 86-108, jan/jun 2019. 
utilizadas para garantir a alocação de recursos e a distribuição de renda em vários lugares". O autor entende, contudo, ser possível aproximar esses mercados reais daqueles idealizados pela teoria econômica.

As instituições para North (1990) se dividem em regras formais, limitações informais e nas condições de execução das regras. Outra característica salientada das instituições é sua natureza path dependence, condição na qual as decisões enfrentadas em determinadas circunstâncias encontram-se limitadas por decisões passadas, embora as circunstâncias do passado já não sejam relevantes. A questão colocada pela NEI é que a manutenção das regras formais necessárias para garantir o cumprimento dos contratos nas sociedades complexas de hoje é cada vez mais custosa. A solução para esse problema é buscar a existência de limitações informais (normas de conduta, valores e hábitos de pensamento) que garantam o intercâmbio impessoal a baixo custo ${ }^{7}$. Segue dessa proposição todo um campo de estudo baseado na noção de Capital Social. Esse tipo de instituição informal diz respeito " $a$ características da organização social, como confiança, normas e sistemas, que contribuem para aumentar a eficiência da sociedade, facilitando as ações coordenadas” (PUTNAM, 1997, p.177).

O foco específico dos trabalhos sobre Capital Social é procurar relacionar a noção de confiança com o funcionamento do mercado. Neste sentido, autores como Fukuyama (1996) e Lipset e Lenz (2002) passam ao estudo da cultura, salientando a necessidade de promover normas de conduta universais em substituição àquelas compartilhadas por grupos limitados, baseadas, por exemplo, na lealdade familiar e pessoal. Seguindo interpretação de Weber, os autores afirmam serem os vínculos personalistas uma obrigação particularista muito forte nas sociedades pré-capitalistas, mas que é a antítese do mercado. Já os tipos de associação baseados em critérios universais, dão às sociedades os mecanismos de coordenação necessários ao bom andamento econômico, evitando que os mercados sejam apropriados por grupos de poder ou coalizões distributivas.

As formulações de membros do novo institucionalismo, como Douglass North, se enquadram dentro da perspectiva mais liberal do mainstream, por tentarem promover certo tipo de engenharia social pró mercado. A busca é por arranjos institucionais que melhorem os contratos e os direitos de propriedade, de modo a permitir uma maior eficiência da vida econômica.

\footnotetext{
${ }^{7}$ Para aprofundar discussão sobre o trade off entre instituições formais e crescimento, ver Aguilar Filho e Fonseca (2011).

Página 92 Caderno de Ciências Sociais Aplicadas, Vitória da Conquista/BA, vol. 16, nº 27, ano 16, p. 86-108, jan/jun 2019.
} 


\subsection{Estado e Mercado na Tradição Dominante}

A tradição liberal desde Smith, ao teorizar sobre as vantagens do mercado, debruça-se também sobre o papel reservado ao governo e ao Estado. Para o pensador escocês, as atribuições do governo são limitadas, porém significativas, ou seja, proteger os cidadãos de ameaças externas, garantir a justiça e a propriedade e evitar os abusos do poder econômico ${ }^{8}$. Com a identificação das chamadas falhas de mercado pelos keynesianos de orientação neoclássica, a intervenção do governo passa a ser vista como algo que pode melhorar os resultados econômicos, provendo também os chamados bens públicos. Um ramo específico de estudo dentro da própria ortodoxia, a chamada Teoria da Escolha Pública, surge justamente para problematizar os processos políticos associados à tomada de decisão envolvendo tais intervenções. Esta corrente destaca os custos da ação estatal, salientando que "os agentes agem tendo em conta essencialmente os seus interesses pessoais, independente de atuarem no mercado ou na esfera pública" (ALVES e MOREIRA, 2004. p.50). Ou seja, a esfera política e o Estado podem ser comparados, em seu funcionamento, ao mercado econômico.

$\mathrm{Na}$ abordagem da Escolha Pública, o ponto de partida da análise é também o individualismo metodológico, evitando-se qualquer concepção orgânica de entidades como o Estado, este, no caso, é concebido como sendo simplesmente um conjunto de processos criados pelos indivíduos. Para a Escolha Pública é, basicamente, a relação de troca entre ocupantes de cargos e apoiadores a essência da ação do Estado. Uma consequência dessas relações é o desvio de recursos produtivos da economia, fazendo declinar o investimento, a eficiência e o dinamismo econômico. Em decorrência, as investigações dessa Escola são constantemente associadas à necessidade de redução da participação do Estado na economia.

Quanto a NEI, suas conclusões sobre a interação entre economia e sistema político decorrem da incorporação em suas análises de uma série de elaborações da Teoria da Escolha Pública. Para North (1984), o Estado, assim como a igreja, as escolas e as associações diversas, são instituições criadas para atender fins específicos. Na visão deste autor pesa certa noção contratual, na qual o Estado administra direitos de propriedade de acordo com o poder dos súditos. Esses direitos podem ser mais ou menos

\footnotetext{
${ }^{8}$ Os teóricos da escola austríaca, que não fazem parte do mainstream econômico mas são liberais ao extremo, radicalizam esta posição ao afirmar que, como o mercado compatibiliza a diversidade dos interesses em uma sociedade, o objetivo da ordem política deveria ser o de não estabelecer uma escala única de valores. Quanto ao Estado, caberia a este agir no sentido de permitir a consecução de uma maior variedade de propósitos individuais, garantindo as regras da propriedade e da justiça somente.
}

Página 93 Caderno de Ciências Sociais Aplicadas, Vitória da Conquista/BA, vol. 16, nº 27, ano 16, p. 86-108, jan/jun 2019. 
favoráveis à competição econômica e ao crescimento ou gerar barreiras à entrada e favorecer os monopólios. Mais recentemente, North (2009) amplia sua visão sobre a relação entre o sistema político e a economia, apontando para o papel do controle da violência no crescimento econômico. Em sociedades tradicionais, para se garantir crescimento, eram necessárias coalizões políticas entre grupos poderosos, com seus interesses sendo acomodados pela distribuição de privilégios. A transição para as sociedades modernas de alto crescimento só foi possível porque se criou mecanismos institucionais para restringir os usos ilegítimos da violência pelo sistema político.

Outros autores novos institucionalistas, como Acemoglu e Robinson (2012), também salientam o papel da ordem para o crescimento econômico. Na concepção destes, houve certo grau de crescimento nas sociedades antigas devido aos esforços para se criar uma estrutura capaz de produzir riqueza para a elite. O crescimento além desse ponto, entretanto, pode ser prejudicial, ao gerar um processo de "destruição criadora", pondo em risco o próprio poder dessas elites. A Inglaterra rompeu com esse ciclo inaugurando uma fase autossustentada de prosperidade. Isso ocorreu depois de ter promovido, no século XVII, duas revoluções políticas, cujas consequências foram conter o poder das elites melhorando a distribuição dos direitos políticos.

O que une as noções acima, veiculadas à tradição dominante, é certa visão negativa do Estado, sempre oposto à sociedade e ao mercado. Tanto o mercado quanto o Estado são, ademais, pressupostos como estando desenraizados socialmente. Mas até que ponto o Estado se opõe e substitui a iniciativa privada? Até que ponto a burocracia do Estado vai atuar de acordo com os preceitos da Teoria da Escolha Pública? O objetivo da próxima seção é entender como os herdeiros do pensamento institucionalista original respondem e explicam o funcionamento do mercado e sua relação com o Estado.

\section{Mercado e Estado na Economia Política Institucionalista}

Na visão neoclássica, segundo Hodgson (1994), está implícita a noção do mercado como uma espécie de ordem natural, na qual as preferências subjetivas e individuais se relacionam umas com as outras para conduzir a troca física de bens e serviços. A NEI apresenta avanços em relação a esse ponto de vista. Sua falha está por tratar a questão da emergência das instituições apenas em termos da sua eficiência comparativa. Ademais, o equívoco, compartilhado por todas as perspectivas que defendem uma ordem social dirigida pelo mercado, é desconsiderar a relatividade histórica e social e os contextos específicos nos quais essa instituição surge.

Página 94 Caderno de Ciências Sociais Aplicadas, Vitória da Conquista/BA, vol. 16, n 27, ano 16, p. 86-108, jan/jun 2019. 
Com relação ao institucionalismo político, esse descende da tradição original de Thorstein Veblen e John R. Commons, dominante no pensamento acadêmico americano na primeira metade do século XX. A principal oposição dos institucionalistas políticos é quanto à suposição de certos grupos dentro do mainstream em relação ao mecanismo de mercado como sendo o guia ótimo da alocação social de recursos. Apontam, em contraposição, que essa alocação é determinada pela estrutura organizacional da sociedade. Com isto, propõem o estudo sistêmico e holístico de todas as instituições que afetam a economia, destacando a atuação das forças sociais que contribuem para a formação dos mercados e que modelam o exercício das escolhas individuais, tudo isto num contexto evolucionário de mudança social.

Para o institucionalismo político, o comportamento humano está ligado a padrões e regras, mais precisamente aos hábitos e as rotinas existentes em uma determinada sociedade (HODGSON, 1994). A importância dos hábitos, segundo Hodgson (1994), associa-se à impossibilidade de uma deliberação consciente sobre todos os aspectos do comportamento. Neste caso, eles servem para lidar com a complexidade da vida cotidiana. Estes hábitos, contudo, não devem ser assumidos como representando uma "resposta ótima aos custos de informação, a outras restrições e custos de processar informação, como queriam os autores neoclássicos e da NEI” (RUTHERFORD, 1996, p. 79).

A obra de Karl Polanyi se constitui em um meio termo em relação ao institucionalismo original (IEO) e a nova sociologia econômica. Esta última, ao se situar entre as tradicionais fronteiras disciplinares da economia e da sociologia, se apoia nos escritos de Karl Polanyi para criticar as teorias da escolha racional e a tentativa recente de socialização do agente econômico pela NEI. Polanyi (2000 e 2012) se destaca, principalmente, por mostrar o enraizamento social do mercado, ao mesmo tempo em que critica duas falácias economicistas. A primeira procura reduzir o âmbito do econômico aos fenômenos de mercado, simplificando a história humana. A segunda amplia o conceito de mercado a ponto de atribuir explicação única para os demais fenômenos.

Em contraposição à tendência de apresentar o mercado como uma instituição universal, baseada em uma propensão humana universal, Polanyi (2012) se apoia numa noção substantiva de economia, concebida como meio pela qual os homens em distintas sociedades organizam a produção para satisfazer suas necessidades. Neste sentido, a atividade econômica é universal, o mercado, por seu turno, não. Este não se confunde nem mesmo com a "troca", ${ }^{9}$ movimento de apropriação mútua de

\footnotetext{
${ }^{9}$ O comércio é o meio pacífico de adquirir bens que não se encontram disponíveis in loco. O comércio e os usos do dinheiro, instrumentos do funcionamento do mercado, são elementos estranhos à ordem social até o advento da sociedade de
}

Página 95 Caderno de Ciências Sociais Aplicadas, Vitória da Conquista/BA, vol. 16, n 27, ano 16, p. 86-108, jan/jun 2019. 
bens entre agentes, realizado na maioria das vezes com taxas fixas. Os mercados modernos, com preços flutuantes, são instituições complexas, abrangendo grupos de oferta ou de procura, ou ambos, reunidos em condições onde estejam garantidas condições especiais como a concorrência, a lei e o costume.

De acordo com Polanyi (2000 e 2012), apenas para a história recente e no mundo ocidental, o mercado teria dominado a vida econômica. Esse movimento contou com a participação do Estado e dependeu de eventos que produziram a interdependência geral do sistema de preços. Foram relevantes neste sentido: a penetração do comércio externo, substituindo os mercados pequenos com preços estáveis por mercados com preços flutuantes para a terra e o trabalho; e a introdução de máquinas complexas especializadas no sistema comercial, de onde se passou a exigir maior controle da cadeia de suprimentos assim como a mercantilização de todas as etapas da produção.

A outra falácia a que se refere o pensador húngaro é quanto ao entendimento que os economistas defensores da noção de mercado livre têm da relação entre o domínio do econômico e o do social. A ideia de enraizamento usada pelo autor indica que as trocas sempre tiveram suas motivações ditadas por considerações diversas, como a política, a estética, a religião ou outras motivações sociais. Com a possibilidade de organizar os seres humanos como simples quantidades de matérias primas e combiná-los com os fatores naturais à mercê de supervisão, gerou-se uma sociedade de mercado. O significado disso é que foi criado na prática o que se preconcebia como ideal, a identidade entre mercado e sociedade.

Chang (2002), apoiando-se na Escola Histórica Alemã e no IEO, ao mesmo tempo em que ressalta o caráter histórico e social do mercado, levanta várias objeções às teorias liberais que sustentam a concepção de mercado livre. O autor ilustra seus argumentos apresentando três exemplos históricos de como esses limites são socialmente construídos. O primeiro é que, até meados do século XIX, qualquer defesa da abolição da escravidão era considerada tentativa de intervenção contra o livre direito de explorar a propriedade, desde então passou a prevalecer o direito fundamental de qualquer membro da sociedade de não trabalhar contra a própria vontade. Outro caso é o do trabalho infantil, a discussão sobre o direito das crianças não trabalharem deixou a algum tempo de constar na agenda política dos países desenvolvidos, enquanto nos países subdesenvolvidos as tentativas de regulamentação são vistas como intervenção contra o direito dos produtores empregarem de forma mais lucrativa a mão de obra. Por fim, o autor menciona o embate recente para impor limites à exploração ambiental.

mercado. O dinheiro sempre foi usado mais em trocas de longa distância e o comércio, com seu caráter bidirecional, apenas existiu também nesta perspectiva.

Página 96 Caderno de Ciências Sociais Aplicadas, Vitória da Conquista/BA, vol. 16, n 27, ano 16, p. 86-108, jan/jun 2019. 
Ademais, a separação entre a esfera de atuação do mercado e a ação estatal, segundo Chang (2002), é complicada de ser estabelecida, pois essa varia de sociedade para sociedade. O argumento ortodoxo de que as intervenções do Estado devem ocorrer apenas quando houver "falhas de mercado", também é criticado, dada a imprecisão deste conceito. Em seu lugar Chang (2002, p.107) ressalta a importância das regulamentações estatais em dar suporte ao intercâmbio econômico, estas definem inclusive "quem pode participar de que mercados e em que termos ${ }^{10}$ ". Por fim, a crítica do autor recai sobre as razões dadas pelos ortodoxos para justificar as privatizações, a saber, restrição orçamentária ilimitada, comportamento free rider e relação agente principal. Na sua visão, estes problemas não são específicos do Estado, podendo ser encontrados com frequência nas empresas privadas (CHANG, 2009).

A concepção ortodoxa sobre a relação entre mercado e Estado também é criticada por Evans (1993), enfatizando que no capitalismo o Estado é mais complementar do que concorrente das empresas e do mercado. A organização estatal é importante para salvaguardar o mercado e propiciar as bases da acumulação de capital. A análise de Evans (1993) recai principalmente sobre a atuação do quadro administrativo. $\mathrm{O}$ autor coloca-se em oposição tanto à visão dos membros deste como caçadores de rendas, quanto com relação à crença weberiana segunda a qual os mesmos estão munidos de compromissos estatutários com o cumprimento do dever, só por ocuparem o cargo.

Evans (1993) complementa Weber ${ }^{11}$ em seu estudo, constatando a existência, em muitos casos, de elementos não formais que dão sustentação à meritocracia dentro do Estado. Tais elementos podem provir, por exemplo, de grupos de competência pela criação da identidade corporativa. Com relação à vigência da lógica particularista e do patrimonialismo na relação com o Estado, Evans (1993) mostra que estes ocorrem justamente para servidores atuando em Estados 'autônomos' ou desenraizados, que é quando as metas desta organização não derivam da agregação de interesses sociais. Para estes casos, os serviços públicos perdem o seu caráter de universalidade, passando a ser apropriados por grupos de interesse dentro desta própria organização, virando moeda de troca para a reprodução destes grupos e para a continuidade de determinadas relações de poder.

\footnotetext{
${ }^{10}$ A existência de mercados não competitivos, onde predominam monopólios, é apresentada como falha de mercado para os neoclássicos, mas na tradição política muitas vezes pode ser caracterizada como condição inevitável de uma economia dinâmica, impulsionada por inovações tecnológicas.

${ }^{11}$ Para Weber (1999), o Estado moderno é uma organização semelhante em diversos aspectos com as formas historicamente anteriores de poder. Isto por se constituir em uma relação de dominação de homens sobre homens, apoiada por meio da coação legítima. A diferença reside em que, enquanto a dominação tradicional estava apoiada em fundamentos tradicionais como a autoridade do costume, do carisma, a dominação nos Estados modernos baseia-se mais na obediência em virtude da legalidade da crença na validade de estatutos legais.
}

Página 97 Caderno de Ciências Sociais Aplicadas, Vitória da Conquista/BA, vol. 16, n 27, ano 16, p. 86-108, jan/jun 2019. 
A definição de Hodgson (1994, p.175), resume bem o que é o mercado para os institucionalistas herdeiros da IEO: "um conjunto de instituições sociais em que se verifica normalmente um grande número de trocas de mercadorias de um tipo específico, sendo essas trocas facilitadas e estruturadas por essas instituições". Nesta concepção estão resguardados os elementos que tornam o intercâmbio possível, como a difusão da informação, os consensos sobre preços e as garantias de propriedade. Não faz parte da tradição dos herdeiros de Veblen, portanto, a contraposição privado versus estatal, que idealiza na privatização ou na estatização das empresas, dos espaços e da economia, a panaceia geral para resolver todos os problemas econômicos. Os institucionalistas ressaltam antes, o caráter "público" do mercado e do Estado, chamando a atenção para o maior grau de "empoderamento" ${ }^{12}$ " de tais instituições por parte da sociedade.

\section{O funcionamento do mercado no Brasil segundo a visão dos intérpretes}

Existem muitos autores pertencentes às mais diversas tradições teóricas, os quais se pode denominar de Intérpretes do Brasil. Apesar de as suas contribuições figurarem muitas vezes de forma assistemática e com teor relativamente ensaístico, estas continuam sendo um modo original e sempre atual de ver o país. Diante da diversidade e dificuldade em selecionar abordagens, procurou-se analisar a obra principal daqueles cujo pensamento está associado às correntes teóricas mais tradicionais das Ciências Sociais, como o marxismo, a análise weberiana e a antropologia cultural.

O destaque inicial vai para Gilberto Freyre, considerado um dos mais importantes demiurgos do Brasil. Em Casa Grande \& Senzala (2011 [1933]), o autor apresenta uma visão bastante otimista, na medida em que reconhece ser a sociedade brasileira a primeira criada nos trópicos com características nacionais e qualidade de permanência. Uma influência marcante no pensamento de Freyre é a antropologia cultural de Franz Boas, permitindo-lhe contrapor às questões raciais e ao determinismo geográfico o peso dos fatores culturais. Permite também reconhecer a importância das questões econômicas salientadas pelos marxistas, mas imbricando seus resultados à cultura. No Brasil colônia, segundo Freyre (2011), a família patriarcal foi a unidade principal da colonização. A estrutura institucional do tipo de sociedade descrita pelo escritor pernambucano aproxima-se em alguma medida do que Polanyi (2000) denominou de domesticidade, ou seja, cada unidade produtiva funcionava de modo quase autossuficiente - o lucro era visado apenas no comércio exterior. Não havia mercados

\footnotetext{
12 Esse termo refere-se à conquista da condição e da capacidade de participação, o que implica na socialização do poder entre os cidadãos.
}

Página 98 Caderno de Ciências Sociais Aplicadas, Vitória da Conquista/BA, vol. 16, n 27, ano 16, p. 86-108, jan/jun 2019. 
internamente porque, além da autossuficiência da unidade, nem o trabalho e muito menos a terra constituíam-se em mercadorias.

Uma característica peculiar da sociedade colonial descrita em Casa Grande \& Senzala foi o ambiente de intimidade criado pelo domínio patriarcal sobre escravos, mulheres e agregados. $\mathrm{Na}$ ausência dos padrões habituais, legais e políticos necessários para o funcionamento do mecanismo de oferta-procura-preço (HODGON, 1994), foi o ambiente de intimidade que, por um lado, acomodou as diferentes concepções de mundo e a noção de propriedade privada e, por outro, fez das relações pessoais a principal moeda de troca na sociedade. Tais relações constituíram-se, para o homem livre e pobre, a possibilidade de ganhar a vida e dispor de cargos importantes e, para os escravos, a oportunidade de dirimir a opressão da escravidão, pois a "casa-grande fazia subir da senzala para o serviço mais íntimo e delicado dos senhores uma série de indivíduos... cujo lugar na família ficava sendo não o de escravos mas o de pessoas de casa” (FREYRE, 2011, p. 435).

Em contraste com o dogmatismo de certas vertentes marxistas, alguns Intérpretes do Brasil fazem uso da sociologia weberiana para entender o descompasso histórico do país ${ }^{13}$. Para Sérgio Buarque de Holanda em Raíres do Brasil (1999 [1936]), a vigência do personalismo individualista e amoral seria a causa da debilidade das formas de organização e associações que implicam solidariedade e ordenação entre os Ibéricos. Para o Brasil, o autor acrescenta o peso das relações de simpatia desenvolvidas na esfera doméstica. O brasileiro, por ser formado dentro de um ambiente de intimidade, seria incapaz de se desvincular dos laços familiares a partir do momento em que se torna um cidadão.

Sérgio Buarque emprega os termos personalismo e patriarcalismo em um sentido parecido ao de "hábitos de pensamento" empregado por Hodgson (1994). Para este último, dada a incapacidade de deliberação consciente sobre todos os aspectos da vida, as decisões passam a ser tomadas não em função de um cálculo de utilidade ótima, mas por algum critério de "satisfazimento". Este se baseia no comportamento habitual e rotineiro, em outros termos, nas instituições. Em consequência, o mercado, de acordo com Hodgson (1994), é uma instituição cuja existência no presente e no futuro está conectada à ação passada dos agentes. Para Holanda (1999, p.148-149), o tipo de hábito mental

\footnotetext{
${ }^{13}$ Estes autores buscaram em Max Weber, principalmente, enfatizar a complexa relação entre as várias dimensões política, social e econômica, evitando explicações do tipo monocausais. Para Weber (2001), uma ação pode ser definida como econômica em vários sentidos, pode, por exemplo, ser motivada por fatores econômicos ou produzir consequências econômicas. Ademais, o autor não descura da influência das variáveis políticas quando trata com a economia. Como salienta Raud (2005), na concepção de Weber sobre o mercado está presente tanto a dimensão econômica, na qual coexistem as relações orientadas para parceiros e concorrentes, quanto a política, onde reina a competição e a noção de luta e de poder.
}

Página 99 Caderno de Ciências Sociais Aplicadas, Vitória da Conquista/BA, vol. 16, n 27, ano 16, p. 86-108, jan/jun 2019. 
desenvolvido pelo brasileiro dificulta a adesão às formas modernas de associação, como o mercado, baseadas na concorrência e na impessoalidade:

O desconhecimento de qualquer forma de convívio que não seja ditada por uma ética de fundo emotivo representa um aspecto da vida brasileira que raros estrangeiros chegam a penetrar com facilidade. E é tão característico, entre nós, essa maneira de ser, que não desaparece sequer nos tipos de atividade que devem alimentar-se normalmente da concorrência. Um comerciante da Filadélfia manifestou certa vez (...) que, no Brasil como na Argentina, para conquistar um freguês tinha necessidade de fazer dele um amigo.

Com o personalismo e o patriarcalismo produzindo equívocos na interpretação e atuação sobre a realidade econômica, Holanda (1999, p.146) constata também a ingerência da ordem familiar nos negócios públicos, o patrimonialismo. Segundo o autor "Não era fácil aos detentores das posições públicas de responsabilidade, formados por tal ambiente [familiar], compreenderem a distinção fundamental entre os domínios do privado e do público”.

Assim como Sérgio Buarque de Holanda, Raymundo Faoro em Os Donos do Poder (1997 [1958]), também vê na colonização a predominância de certa racionalidade oposta à capitalista. De acordo com Faoro (1997) houve na história brasileira várias limitações à atividade econômica fundada na propriedade privada e na liberdade. A razão está no modo como ocorreu a colonização, com "Portugal buscando no país um prolongamento passivo das suas instituições, armadas para criar do alto, por obra da moldura jurídica, a vida política” (FAORO, 1997, p.148).

Diferentemente das instituições desenvolvidas pelo capitalismo inglês e francês, as portuguesas tinham como característica a concentração de poderes nas mãos do Rei e do quadro administrativo. Nesse tipo de dominação, patrimonialista, 'o cargo' e a distribuição de títulos e comendas constituem-se nos principais instrumentos de cooptação das classes sociais. Com o Estado reduzido a empresa do príncipe, a atividade produtiva desenvolveu-se debaixo do favoritismo e da tutela oficial. Os mercados, consequentemente, tornaram-se uma relação reservada, privilegiada ${ }^{14}$. Como herdeiro dessa tradição, o legado para o Brasil foram os problemas permanentes de dependência, com restrição ao desenvolvimento do mercado interno ${ }^{15}$.

\footnotetext{
14 Segundo Galvan (2001), a própria moeda quando de sua difusão, tinha por finalidade a apropriação pelo Rei da riqueza através de um aparelho de sucção montado pelo Estado via monopólios, companhias de comércio e pacto colonial.

${ }^{15}$ No Brasil a colonização e a conquista do território tiverem sua fonte na vontade da burocracia, expressa na atividade "legalista" e regulamentar.
}

Página 100 Caderno de Ciências Sociais Aplicadas, Vitória da Conquista/BA, vol. 16, n² 27, ano 16, p. 86-108, jan/jun 2019. 
É importante ressaltar que em Faoro (1997) a apropriação das rendas estatais pelo quadro administrativo não é algo inerente ao funcionamento do Estado, como ocorre para a Teoria da Escolha Pública. O patrimonialismo português e brasileiro deriva de condições históricas bem específicas, com o Estado aproximando-se muito dos Estados 'desenraizados' estudados por Evans (1993), onde as metas do quadro administrativo não estão de acordo com a agregação de interesses sociais. Nestes casos, o patrimonialismo existente no sistema político não dá suporte para a existência de mercados econômicos fundados na concorrência e na impessoalidade.

$\mathrm{Na}$ perspectiva marxista, corrente de pensamento social mais influente do século $\mathrm{XX}$, a economia não se confunde com a instituição mercado, mas engloba as formas como os seres humanos desenvolvem suas relações de trabalho e distribuição no processo de produção e reprodução da vida material ${ }^{16}$. Caio Prado Jr. ${ }^{17}$ inicia sua análise marxista em "Formação do Brasil Contemporâneo" (2011 [1942]) tendo como ponto de partida a noção de "sentido da colonização". Este "sentido" deve ser buscado no contexto da expansão comercial e marítima europeia, iniciada no século XI e interrompida após fechamento das tradicionais rotas comerciais no século XV.

$\mathrm{O}$ autor credita o pioneirismo aos portugueses tanto pelas descobertas no além-mar quanto por terem introduzido formas de produção na colônia conectando-as à economia reprodutiva europeia. Diante do lucro mercantil esperado, o objetivo de estabelecer colônias de povoamento foi secundário quando comparado com o das colônias inglesas no norte do continente. Num contexto de mercantilismo, os mercados na colônia desenvolveram-se como negócio da metrópole, administrados no interesse desta, com o exclusivo metropolitano (a metrópole compra barato da colônia e vende caro) figurando como principal mecanismo de extração do excedente na colônia. Segundo Prado Jr. (2011, p. 131):

\footnotetext{
${ }^{16} \mathrm{O}$ mercado, instância originalmente responsável pela circulação dos excedentes via comércio de longa distância, passa na história recente a ganhar importância crescente na intermediação da vida econômica. No capitalismo, as relações mercantis acabam se constituindo numa fase necessária do processo de acumulação do capital; etapa onde a força de trabalho, as matérias primas e as mercadorias são em geral contratadas, realizando-se o lucro capitalista. Nessa esfera, segundo o próprio Marx (2013), as relações sociais aparecem de forma mistificada, como paraíso onde reina a liberdade, a igualdade e o utilitarismo.

${ }^{17}$ Caio Prado Jr. inaugura uma tradição denominada de circulacionista na explicação da sociedade colonial, na qual a forma de inserção no comércio determina certa forma de capitalismo. Além dele, fazem parte desta tradição Fernando Novais e Celso Furtado (este último não marxista). Outros autores como Jacob Gorender e Ciro Flamarion chamam a atenção para a necessidade de se ter em conta o grau de desenvolvimento interno das forças produtivas na caracterização de modos de produção específicos.
}

Página 101 Caderno de Ciências Sociais Aplicadas, Vitória da Conquista/BA, vol. 16, n 27, ano 16, p. 86-108, jan/jun 2019. 
Todos os atos da administração portuguesa com relação à colônia têm por objetivo favorecer aquelas atividades que enriqueciam o seu comércio, e pelo contrário opor-se a tudo mais. Bastava que os colonos projetassem outra coisa que ocupar-se em tais atividades e, lá intervinha violentamente a metrópole a chama-los à ordem: o caso das manufaturas, da siderurgia, do sal, de tantos outros, é bastante conhecido.

Aquilo que é dito por Caio Prado Jr. está de acordo com a afirmação de Chang (2002), para quem as instituições são importantes não apenas para determinar quem pode participar das trocas, mas de que modo a participação deve ocorrer. No Brasil, a restrição ao mercado ocorreu tanto pelo lado da oferta quanto da demanda. Com relação à oferta, a estrutura produtiva montada com base no trabalho escravo, latifúndio e na extroversão, gerava pouca circulação de mercadorias internamente. Do ponto de vista da demanda, a concentração de renda impulsionava grande influxo de importados por parte da elite e baixo consumo por parte da população voltada à subsistência. A consequência, segundo Prado Jr. (2011), teria sido o atrofiamento do mercado interno com carestia geral de bens e viveres, algo recorrente nas cidades brasileiras. Como se não bastasse, esse sistema se reproduziu historicamente com o país desempenhando o papel de fornecedor de produtos para abastecer o mercado europeu em detrimento do mercado interno.

A obra de Roberto DaMatta constitui-se numa tentativa de síntese das perspectivas de Gilberto Freyre e Caio Prado Jr. Segundo o autor, ambas são representantes de duas maneiras diferentes e não contraditórias de ver o Brasil. Uma foca na cultura e nos costumes e a outra nas leis e na lógica da economia política. Ambas falam de uma sociedade que atua por meio de códigos complementares, mas não fixos e invariantes, da casa e da rua. Dependendo das circunstâncias específicas, um desses polos pode "totalizar" o outro. A consequência da existência de espaços de significação social diferentes no Brasil, segundo DaMatta (1985, p. 82-83), é que toda instituição no país "está sujeita a dois tipos de pressão, uma universalista, que vem das normas burocráticas e legais, a outra é determinada pelas redes de relação". A desconfiança que o brasileiro tem das normas universalistas, segundo o autor advém do fato de o país não ter vivenciado uma revolução individualista que instituísse um código de conduta hegemônico, fundado na ideia de cidadão. Ao contrário, o Estado teve de assumir o comando do processo de modernização e transformação, criando leis fundadas a partir de seus próprios mecanismos de mudança, progresso e controle.

De acordo mais uma vez com Hodgson (1994), qualquer mercado minimamente organizado deve exibir consensos em torno de questões básicas como preços, expectativas e direitos. No caso do

Página 102 Caderno de Ciências Sociais Aplicadas, Vitória da Conquista/BA, vol. 16, n 27, ano 16, p. 86-108, jan/jun 2019. 
Brasil, com o predomínio de vários códigos de conduta, vários mercados passaram a operar simultaneamente,

Alguns são financiados pelo Estado e seus empresários desfrutam todos os lucros e nenhum risco. Outros operam na dura base da lei da oferta e da procura. E há, ainda, aquela esfera dominada pelos letrados, tecnocratas ou, para usarmos a expressão definitiva de Raymundo Faoro, os "donos do poder", esses que vivem num universo sem competição, pagos pelo Estado e sustentados pelos misteriosos laços de simpatia e lealdade (DAMATTA, 1985, p.21).

Uma abordagem mais recente, da qual se pode depreender elementos do enraizamento social do mercado, é a de Souza (2015). O autor critica tanto as vertentes economicistas do pensamento brasileiro, por desprezarem os elementos simbólicos da reprodução social, quanta a vertente culturalista, pela incapacidade de reconhecer que o mundo moderno em sua unidade é produto do Estado e do mercado e da força destes em moldar valores, comportamentos e preferências. A obra de Pierre Bourdieu é fundamental para o argumento de Souza (2015), na medida em que ela permite compreender o personalismo, o patriarcalismo, o patrimonialismo e o jeitinho como males da modernidade - compondo o capital social de qualquer sociedade - e não como especificidades de um país. No caso do Brasil, os grupos de alta renda sempre dispuseram de relações privilegiadas que lhes permitiram o acesso mais fácil aos recursos escassos da sociedade, possibilitando a reprodução da sua condição de classe. Esses recursos são o capital econômico, simbólico e cultural. Nas palavras do próprio Souza (2015, p. 86) "É o acesso a esses “capitais impessoais" que pode realmente explicar o acesso privilegiado a de fato tudo que todos nós mais desejamos na vida. Eles pré-decidem nossa sorte, nosso azar, nosso sucesso, nosso fracasso". O ponto central salientado pelo autor é que os desvios no funcionamento do mercado e do Estado devem-se menos às pessoas e mais à estrutura extremamente desigual e excludente da distribuição da riqueza no Brasil.

O foco de Souza (2015) nas questões da socialização colocam seus escritos em correspondência com o pensamento institucionalista, pois os autores dessa corrente salientam, do mesmo modo, as preferências e interesses como relacionados às instituições. No caso do capitalismo moderno, salientam a forma como as preferências são influenciadas pelos interesses corporativos das grandes empresas. Galbraith (1988), em particular, destaca a capacidade destas em estabilizar os mercados, ao controlar preços e ao condicionar artificialmente a demanda. A questão das desigualdades também ocupa o pensamento institucionalista, considerada por estes um empecilho à cooperação social; deste modo, o

Página 103 Caderno de Ciências Sociais Aplicadas, Vitória da Conquista/BA, vol. 16, n 27, ano 16, p. 86-108, jan/jun 2019. 
mote desta corrente é por reformas sociais radicais com vistas a promover maior inclusão e empoderamento social.

Em síntese, não seria difícil a nenhum dos Intérpretes corroborarem a afirmação de Chang (2002) de que as instituições de uma sociedade estruturam as trocas econômicas. O que há de original na perspectiva de cada um, vis a vis ao pensamento institucionalista, é terem especificado o contexto social e político brasileiro e o modelo mental segundo o qual os agentes sociais baseiam sua conduta econômica. Sérgio Buarque e Gilberto Freyre salientam o predomínio dos interesses das oligarquias rurais e a forma como o ambiente de intimidade criado a partir das relações no ambiente rural afeta o funcionamento das instituições modernas como mercado e Estado. Raymundo Faoro salienta o predomínio de interesses de grupos de poder dentro do Estado, distorcendo os incentivos para a sociedade. Caio Prado Jr. foca nas determinações do tipo de economia política estabelecida nos trópicos, cuja função era produzir riqueza para a metrópole com a consequente atrofia do mercado interno. DaMatta tenta fazer uma síntese, reconhecendo ser todas faces diferentes de uma mesma forma de ver o país. No seu entendimento, sociedades como a brasileira, caracterizadas pela estratificação ocupacional e existência de espaços privilegiados, tenderiam a criar diferentes mercados, alguns fundados na impessoalidade, outros em privilégios. Já a interpretação mais recente de Souza (2015) agrega outros tipos de entendimento sobre o Brasil, ao mostrar que os mercados se desenvolveram no país fundados na estrutura extremamente desigual e excludente da distribuição da riqueza, sendo apropriados por interesses particularistas, o da elite. Afirma, em consequência, que é essa apropriação desigual a maior responsável pelas falhas no funcionamento do mercado.

\section{Conclusão}

$\mathrm{Na}$ tradição do pensamento econômico dominante, mercado e Estado são postos em constante oposição. Em decorrência desta cisão, fundamentou-se a proposição teórica de que os mercados são "em geral” a melhor forma de organizar a produção, permitindo às sociedades alcançar a máxima eficiência alocativa e produtiva. O pré-requisito fundamental para a existência de mercados eficientes, dentro desta tradição, é a garantia de propriedade e de acesso livre e universal dos agentes econômicos ao sistema de trocas.

Já com o pensamento institucionalista surge a necessidade de ultrapassar os falsos antagonismos postos pela abordagem econômica dominante. Deste modo, o institucionalismo político chama à atenção para o enraizamento do mercado, enfatizando seu caráter histórico e social. Portanto, não

Página 104 Caderno de Ciências Sociais Aplicadas, Vitória da Conquista/BA, vol. 16, n² 27, ano 16, p. 86-108, jan/jun 2019. 


\section{- Cadernos de Ciénclas SOCIAIS APLICADAS}

apenas as considerações quanto à eficiência do mercado, mas seus limites, bem como aquilo que é objeto de trocas, passam a depender do contexto e do arranjo sociopolítico existente. Com o intuito de entender o ambiente institucional e as especificidades do mercado no Brasil, o presente artigo utilizou a elaboração dos chamados Intérpretes da realidade brasileira. Uma constatação importante da leitura destes é que o tipo de enraizamento social existente no Brasil fez do mercado uma 'instituição privada', no sentido de ser ele apropriado por grupos particularistas.

Até recentemente as visões de Brasil estavam marcadas pelo dualismo entre as tradições culturalista e economicista. Para os culturalistas, o enraizamento do mercado se dá em um contexto em que predomina uma herança personalista portuguesa que cria sérias dificuldades para se sustentar uma esfera pública dissociada da ordem privada. Deriva desta perspectiva certo pessimismo, dado que mercado e Estado, instituições modernas impessoais por excelência, operam sempre distorcidos pela ineficiência e corrupção próprias da nossa mentalidade. Neste caso, não há nenhuma menção à estrutura extremamente desigual e excludente da distribuição de renda no país e a forma como essa desigualdade afeta o funcionamento do mercado e do Estado. Já para a vertente da economia política, são os interesses mercantis impostos inicialmente pela metrópole que fizeram do mercado interno uma relação privilegiada, baseada desde a origem na exclusão pelo latifúndio e escravidão. Neste caso, o que falta a essa última interpretação é destacar os elementos simbólicos envolvidos na reprodução social. Mesmo com as condições abertas pelo fim da escravidão e com o surgimento de certo liberalismo interno, o mercado nunca se constitui em uma ordem de acesso aberto porque as disposições de comportamento necessárias à competição são um elemento de classe. Esta é exatamente a crítica de Souza (2015), também corroborada pelo presente trabalho, que destaca que a desigualdade na posse dos diferentes capitais é uma condição funcional da sociedade, que se expressa no mercado por meio da compra a baixo custo dos elementos necessários à reprodução das diferentes posições de classe. As distorções no funcionamento mercado advêm portanto da distribuição desigual dos capitais econômico, simbólico e social, este último fonte maior da apropriação dos recursos públicos pela elite, já que esta tem acesso mais fácil à rede de relações e ao poder do Estado.

Página 105 Caderno de Ciências Sociais Aplicadas, Vitória da Conquista/BA, vol. 16, n 27, ano 16, p. 86-108, jan/jun 2019. 


\section{Referências}

ACEMOGLU, Daran; ROBINSON, James. Why Nations Fail. The Origins of Power, Prosperity, and Poverty. Crown Business, New York, 2012.

AGUILAR FILHO, Hélio; FONSECA, Pedro. "Instituições e Cooperação Social em Douglass North e nos Intérpretes Weberianos do Atraso Brasileiro". Revista Estudos Econômicos. São Paulo, vol. 41, no 3, Jul/Set, 2011.

CHANG, Ha-Joon. Rompendo o modelo: uma economia política institucionalista alternativa à teoria neoliberal do mercado e do Estado. In: ARBIX, G. et ali (Orgs.) Brasil, México, África do Sul, Índia e China: diálogo entre os que chegaram depois. São Paulo: Editora UNESP, EDUSP, 2002.

. Maus Samaritanos: o mito do livre-comércio e a história secreta do capitalismo. Rio de Janeiro: Elsevier, 2008.

DAMATTA, Roberto. A Casa \& a Rua: espaço, cidadania e mulher no Brasil. Rio de Janeiro: Rocco, 1985.

EVANS, Peter. "O Estado como Problema e Solução". São Paulo: Lua Nova. Revista de Cultura e Política, n. 28-29, abril, 1993.

FAORO, Raymundo. Os Donos do Poder: formação do patronato político brasileiro. São Paulo: Globo, 10 ed, 1997[1958].

FREYRE, Gilberto. Casa Grande \& Senzala. São Paulo: Global Editora, (2011[1933]).

FRIEDMAN, Milton. Capitalismo e Liberdade. São Paulo: Nova Cultural, 1985.

FUKUYAMA, Francis. Confiança: valores sociais e criação de prosperidade. Lisboa: Gradiva, 1996.

GALBRAITH, John. K. O Novo Estado Industrial. $3^{\text {a }}$ ed. São Paulo: Nova Cultural, 1988.

GALVAN, Cesare. Colônia, Estamento, Capitalismo Político - um enriquecimento de idéias na leitura livre de Faoro. VI Encontro Nacional de Economia Política. Fundação Getúlio Vargas, SP. 12 a 15 de junho de 2001.

HODGSON, Geoffrey. Economia e Instituições: manifesto por uma economia institucionalista moderna. Oeiras: Celta Editora, 1994.

HOLANDA, Sérgio. Raízes do Brasil. 26ª edição. São Paulo: Companhia das Letras, 1999 [1936].

LAWSON, Tony. Essays on the nature and state of modern economics. New York: Routledge, 2015.

LIPSET, Seymour; LENZ, Gabriel. “Corrupção, Cultura e Mercados”. In: HARRISON, Lawrence;

Página 106 Caderno de Ciências Sociais Aplicadas, Vitória da Conquista/BA, vol. 16, n 27, ano 16, p. 86-108, jan/jun 2019. 
HUNTINGTON, Samuel. (Org.) A Cultura Importa: os valores que definem o progresso humano. Rio de Janeiro: Editora Record, 2000.

MARX, Karl. O Capital. Livro 1. São Paulo: Boitempo Editora, 2013.

MOREIRA, José; ALVES, André. O que é a Escolha Pública? Para uma Análise Económica da Política. Cascais: Principia, 2004.

NORTH, Douglass. "Markets and Other Allocation Systems in History: the challenge of Karl Polanyi". Journal of European Economic History, 6: 703-716, Winter, 1977.

Institutions, Institutional Change and Economic Performance. New York: Cambridge University Press, 1990.

NORTH, Douglass; WALLIS, John; WEINGAST, Barry. (2009). Violence and Social Orders: a conceptual framework for interpreting recorded human History. New York: Cambridge University Press.

NORTH, Douglass. Estructura y Cambio en la Historia Económica. 2 ed. Madrid: Alianza Universidad, 1994.

OLSON, Mancur. A Lógica da Ação Coletiva. São Paulo: EDUSP, 1999 [1965].

POLANYI, Karl. A Grande Transformação: as origens da nossa época. $2^{\mathrm{a}}$ ed. Rio de Janeiro: Elsevier, $2000-10^{a}$ reimpressão.

A Subsistência do Homem e Ensaios Correlatos. (Org. LEVITT, Karl P.) Rio de Janeiro: Contraponto, 2012.

PRADO JUNIOR, Caio. Formação do Brasil Contemporâneo: colônia. São Paulo: Brasiliense, $2011[1942]$.

PUTNAN, Robert. Comunidade e Democracia. A Experiência da Itália Moderna. Rio de Janeiro: Fundação Getúlio Vargas, 1997.

RAUD, Cecilia. "Análise Crítica da Sociologia Econômica de Mark Granovetter: os limites de uma leitura do mercado em termos de redes e imbricação". Política \& Sociedade, n.6, abril, 2005.

RUTHERFORD, Malcon. Institutions in Economics: the old and the new institutionalim. New York: Cambridge University Press, 1996.

SOUZA, Jesse. A Tolice da Inteligência Brasileira. Rio de Janeiro: Casa da Palavra, 2015.

WEBER, Max. Economia e Sociedade: fundamentos da sociologia compreensiva. Brasília: Editora UnB. Parte 1, 1999.

Página 107 Caderno de Ciências Sociais Aplicadas, Vitória da Conquista/BA, vol. 16, n 27, ano 16, p. 86-108, jan/jun 2019. 
Metodologia das Ciências Sociais. Campinas: Editora Cortez-Unicamp, $3^{\mathrm{a}}$ edição, Parte 2, 2011.

Recebido em 30 de novembro de 2018

Aprovado em 05 de abril de 2019

Página 108 Caderno de Ciências Sociais Aplicadas, Vitória da Conquista/BA, vol. 16, n 27, ano 16, p. 86-108, jan/jun 2019. 